\title{
ARTIGO \\ DIREITOS HUMANOS E JUSTIÇA RESTAURATIVA NAS ESCOLAS: O QUE PENSAM OS PROFESSORES?
}

\author{
ANA CAROLINA REIS PEREIRA ${ }^{1}$ \\ http://orcid.org/0000-0003-1727-7439 \\ ÁUREA MARIA GUIMARÃES ${ }^{2}$ \\ http://orcid.org/0000-0003-0230-7906
}

\begin{abstract}
RESUMO: O presente artigo tem por objetivo conhecer o lugar que os direitos humanos e a justiça restaurativa têm na história oral de professores que trabalham na rede estadual da cidade de CampinasSP. Entende-se que a mediação de conflitos depende do modo como os processos restaurativos são acolhidos, planejados e executados. Assim, a partir da história oral de vida desses professores, busca-se neste artigo identificar, nas suas narrativas, como foi realizado o uso da justiça restaurativa no contexto escolar. Autores como Foucault, Larrosa, Veiga-Neto, e Pignatelli ajudaram a problematizar as narrativas dos professores envolvendo as práticas restaurativas, reconhecendo nelas predisposições subjetivas que, sendo exercidas com base nos dispositivos de controle, retroalimentam neste lócus a mesma violência que pretendem arrefecer. Entende-se ser necessário encorajar a agência docente, no sentido de estimular entre os educadores uma reflexão permanente, com vistas a transformar rotinas escolares e a refletir sobre o que pode ser feito nas circunstâncias nas quais atuam, cotidianamente.
\end{abstract}

Palavras-chave: Educação em Direitos Humanos; Justiça restaurativa; Violência escolar.

\section{DERECHOS HUMANOS Y JUSTICIA RESTAURADORA EN LAS ESCUELAS: ¿LO QUÉ PIENSAN LOS PROFESORES?}

RESUMEN: El presente artículo tiene por objetivo conocer el lugar que los derechos humanos y la justicia restauradora tienen en la historia oral de vida de profesores que trabajan en la red estatal de la ciudad de Campinas-SP. Entiéndese que la mediación de conflictos depende del modo por lo cual los procesos restauradores son acogidos, planificados y ejecutados. Así, a partir de la historia oral de vida de estos maestros, en este artículo se busca identificar, en sus narrativas, cómo se llevó a cabo el uso de la justicia restauradora en el contexto escolar. Los autores como Foucault, Larrosa, Veiga-Neto, y Pignatelli ayudaron a problematizar las narrativas de los profesores sobre las prácticas restauradoras, reconociendo en ellas predisposiciones subjetivas que, siendo ejercidas sobre la base de los dispositivos de control, retroalimentan en este locus la misma violencia que pretenden enfriar. Defiéndese que es necesario alentar a la agencia docente, en el sentido de estimular entre los educadores una reflexión permanente, con miras a transformar rutinas escolares y a reflexionar sobre lo que puede hacerse en las circunstancias en las que actúan cotidianamente.

\footnotetext{
${ }^{1}$ Universidade Federal do Recôncavo da Bahia; Centro de Formação de Professores, Colegiado de Filosofia. Amargosa, BA, Brasil.<carolina-reis@hotmail.com>

${ }^{2}$ Universidade Estadual de Campinas; Faculdade de Educação. Campinas, SP, Brasil. <auguima@yahoo.com.br>
} 
Palabras-clave: Educación en Derechos Humanos; Justicia restauradora; Violencia escolar.

\title{
HUMAN RIGHTS AND RESTORING JUSTICE IN SCHOOLS: WHAT DO TEACHERS THINK?
}

\begin{abstract}
This article aims to know the place that human rights and restoring justice have in the oral history of teachers working in the state education of the city of Campinas-SP. It is understood that conflict mediation depends on how restorative processes are accommodated, planned, and executed. Thus, from the oral history of these teachers, in this article seeks identify, in their narratives how the use of restorative justice was carried out in the school context. Authors such as Foucault, Larrosa, Veiga-Neto, and Pignatelli helped to problematize the teachers' narratives about the restorative practices, recognizing in them subjective predispositions that, being exercised on the basis of control devices, give back to this locus the same violence that they intend to cool down. Defends it is necessary to encourage the teaching agency and to stimulate among educators a permanent reflection, with a view to transforming school routines and to reflect on what can be done in the circumstances in which they work, every day.
\end{abstract}

KEYWORDS: Education in Human Rights; Restorative justice; School violence. 


\section{INTRODUÇÃO}

Em sendo função da justiça assegurar que os direitos sejam efetivamente respeitados, ela foi incorporada ao rol dos direitos contidos na Declaração Universal dos Direitos Humanos (1948), como também integra os direitos civis e políticos afiançados na Constituição Federal (1988) brasileira, assegurando não apenas o direito de acessar a Justiça, mas também a presunção de inocência ${ }^{4}$ e a defesa em caso de processo penal (BRASIL, 1988, art. 5, inc. LIII, LIV, LV, LVII).

Nessa perspectiva, a justiça restaurativa não pode ser desassociada da doutrina de proteção aos direitos humanos, pois ambas defendem o princípio do respeito à dignidade do ser humano (VITTO, 2005, p. 48) e também os valores da "cidadania democrática" (SCHILLING, 2014, p. 16), haja vista que reivindicam para sua consecução a "[...] constituição de prováveis sujeitos éticos, livres, dotados de palavra, racionais e sensíveis, com direito a ter direitos" (p. 16). Consideramos, portanto, que o debate sobre a relação entre os direitos humanos e a mediação de conflitos pela via das práticas restaurativas possui um potencial emancipador ainda não devidamente realizado em nossa sociedade.

A questão que nos provocou foi como uma proposta que estabelece como seu fundamento o respeito aos direitos humanos dos sujeitos e na qual já está de antemão incorporado um telos de acordo recíproco que estabelece a sua dimensão ética e dialógica se dá em uma sociedade historicamente oligárquica, excludente e autoritária (CHAUI, 2014), na qual uma parte expressiva da população rejeita não só os direitos humanos, como também as reivindicações e as conquistas das forças progressistas nas últimas décadas, conforme evidenciam os dados da pesquisa Direitos humanos: percepcốes da opinião pública, realizada em 2008, pela Secretaria Nacional de Direitos Humanos (SDH/MDH), sobre os significados atribuídos pelos brasileiros a esses direitos (VENTURI, 2010).

Se é papel da justiça fazer com que os direitos sejam efetivamente respeitados, não obstante saibamos que estes ainda não foram devidamente garantidos, como também que não o serão apenas por decreto, ou por Lei, há razões para crer que o sistema de justiça em curso no Brasil tende a reproduzir e perenizar as desigualdades socioeconômicas existentes, pois "quando a impunidade é a norma [...], os cidadãos - no alto e no final da escala social - têm um incentivo para buscar recursos em meios alternativos de obter justiça" (OXHORN; SLAKMON 2005, p. 197).

Em função da sua concepção, os modelos de microjustiça têm sido apontados como alternativas consistentes para a resolução dos conflitos ou crimes de menor potencial ofensivo. Embora seja importante evidenciar que existem situações nas quais a presença policial na escola é inevitável, tais como: atuação do narcotráfico, troca de tiros no entorno escolar e arrombamentos seguidos de roubos ou furtos, discordamos do entendimento, bastante disseminado, sobretudo pela mídia, de que a violência praticada neste lócus será solucionada exclusivamente pelo controle policial e repressivo (RUOTTI; ALVES; CUBAS, 2006, p. 59). Desse modo, tais modelos propõem uma mudança de paradigma do sistema de justiça formal que incide, prioritariamente, na retribuição: a reparação ao invés da punição, e a atuação ativa em detrimento do testemunho passivo.

De fato, a justiça restaurativa é uma proposta alternativa, que pretende, em sua essência, uma mudança radical do que se compreende como resolução dos conflitos, haja vista que todos devem atuar ativamente na elaboração de soluções para a restauração do tecido social rompido. Nada deve ser imposto, e as decisões devem ser atingidas por consenso, donde se percebe que a preocupação da justiça restaurativa não incide na infração à regra, ou no conflito em si, mas no modo como estas questões são abordadas e nas deliberações que lhes são consequentes, ou seja, se reparou os danos e, por conseguinte, a relação entre os sujeitos envolvidos, tanto diretamente (vítima e ofensor), como os que estão de algum modo implicados (família e comunidade) (MELO, 2006, p. 644).

\footnotetext{
${ }^{3}$ O presente trabalho foi realizado com apoio da Coordenação de Aperfeiçoamento de Pessoal de Nível Superior - Brasil (CAPES) - Código de Financiamento 001.

${ }^{4}$ Que estabelece como regra que os sujeitos sejam tratados e considerados inocentes até que se prove o contrário (BRASIL, 1988 , art. $5^{\circ}$, inc. LVII).
} 
Em âmbito escolar, a justiça restaurativa reivindica, para sua consecução, a reorientação da gestão de conflitos. Assim, o consenso que se objetiva atingir não deve ser produzido em situações de desigualdade, mas deve envolver a disposição para ponderar sobre as razões alheias e para reconhecer sua prévia responsabilidade para com o outro, o que a distingue de um mero "reconhecimento de culpa" (MELO, 2006, p. 648). Desse modo, as técnicas restaurativas devem focar na responsabilização ativa dos sujeitos e na restauração dos danos e permitir que se posicionem e reflitam sobre seus atos por meio do diálogo. Contêm, portanto, um profundo teor formativo (MELO, 2006).

A introdução da justiça restaurativa no contexto escolar brasileiro foi pioneiramente realizada pelo município de São Caetano do Sul (SP), em 2005, por meio da execução do projeto "Justiça e Educação: parceria para a cidadania", resultado da cooperação entre os Sistemas de Justiça e de Educação. Posteriormente, esta experiência foi expandida para outros municípios paulistanos, sob a rubrica do Sistema de Proteção Escolar (SPEC), concebido pela Secretaria Estadual de Educação (SEESP), para execução de um conjunto de programas e projetos de prevenção à violência escolar. A justiça restaurativa chegaria, em 2007, ao município de Campinas (SP).

A formação "Cultura Restaurativa e Suas Práticas" foi realizada através de uma parceria entre a Secretaria de Educação do Estado de São Paulo (SEE-SP), a Vara da Infância e Juventude de Campinas (Tribunal de Justiça - TJ/SP) e a Federação das Entidades Assistenciais de Campinas (FEAC). Sua terceira edição foi realizada entre os meses de agosto e dezembro de 2014, para os professores e gestores da rede pública estadual de educação, com o objetivo de promover a cultura da não violência nas escolas públicas de Campinas (SP).

Essa proposta totalizou 32 horas de aulas presenciais, com atividades práticas divididas entre 10 práticas restaurativas e 20 dinâmicas de comunicações não violentas, executadas pelos professores e gestores com seus alunos em suas respectivas unidades escolares de atuação. De modo que esta formação continuada se constituiu como a materialização de uma política de governo, cujo objetivo era subsidiar a prática pedagógica para a prevenção da violência e para a mediação de conflitos no ambiente escolar.

Entretanto, o estímulo ao uso das práticas restaurativas pela rede estadual paulista de educação se defronta com inúmeros impasses e contradições em sua execução, haja vista que o Manual de Proteção Escolar e Promoção da Cidadania (SEESP, 2009a), publicado em 2009 pela Secretaria de Educação do Estado de São Paulo (SEE-SP), contém perguntas e respostas que indicam as regras disciplinares que devem ser adotadas para os casos de insubmissão dos jovens aos preceitos ou normas estabelecidas unilateralmente pelos professores, ou pela direção escolar, igualmente contempladas nas "Normas Gerais de Conduta Escolar" (SEESP, 2009b, art. 3, 5, p. 9-13), a partir das quais todo desvio ou ato de indisciplina deve ser rigorosamente punido.

Ademais, é necessário considerar que os professores não são um grupo homogêneo, e as questões afetivas, políticas e sociais podem se configurar como referências que influenciam na maneira de exercer o magistério, de acatar as regras institucionais e nos modos como processam as informações e as formações que recebem enquanto profissionais da educação.

Considerando que os feixes de sentidos que produzem, ou aos quais aderem, têm origem em sua trajetória social (MARTINS, 2004, p. 109), recorremos à análise da história oral de vida dos professores entrevistados. Importa destacar que, dentre os diversos tipos de história oral, elegemos a história oral de vida justamente por privilegiar em seu campo de estudos a percepção do narrador. De modo que nesta proposta as narrativas não têm que ser definitivas, tampouco verídicas, pois são os elementos subjetivos que emergem da memória que se constituem como seu objeto (MEIHY, 2010).

Assim, a análise da história oral de vida dos 17 professores e mediadores escolares e comunitários egressos do curso "Cultura Restaurativa e Suas Práticas" nos permitiu investigar, na tese de doutorado, a diversidade de concepções que possuem quanto aos princípios afirmados pelos direitos humanos e pela justiça restaurativa e que foram sendo elaborados no decorrer de suas vidas ${ }^{5}$. Neste

\footnotetext{
${ }^{5}$ Este artigo é fruto de tese, cuja investigação foi aprovada pelo Comitê de Ética em Pesquisa da Universidade Estadual de Campinas (CEP / UNICAMP). Número CAAE: 52991015.3.0000.5404.
} 
artigo, fizemos um recorte, optando por não desenvolver com profundidade esse debate, mas enfatizar a seguinte questão: Como, após a conclusão do curso e a partir da análise das narrativas dos professores, foi realizado o uso da justiça restaurativa no contexto escolar?

A pesquisa de campo foi desenvolvida com base em entrevistas gravadas e realizadas nas unidades escolares estaduais de atuação desses sujeitos, entre os meses de julho e novembro de 2015, por sua própria sugestão. Dos 17 professores entrevistados, apenas 4 nasceram em Campinas-SP, 4 eram de outros estados brasileiros, e os demais oriundos de outros municípios do estado de São Paulo. Nesse grupo havia tanto professores como mediadores escolares e comunitários ${ }^{6}$, que possuíam entre 7 e 30 anos em sala de aula, todos em efetiva regência de classe, excetuando-se 2, que se revezavam entre as funções de professor e professor mediador escolar e comunitário. Dentre eles, 8 professores atuavam no Ensino Médio; 6 estavam exclusivamente como professores-mediadores; e 4 lecionavam nos últimos anos dos Ensinos Fundamental e Médio.

No que concerne à sua formação, todos atuavam nas unidades escolares em suas respectivas áreas de formação, ou seja, não foi constatado desvio de função. Nem todos possuíam vínculo efetivo com o Estado. Por questões éticas, decidimos resguardar a identidade dos professores entrevistados, de modo que seus nomes foram todos substituídos. Também por essa razão, não identificamos suas escolas de lotação ${ }^{7}$, tampouco os bairros onde estão situadas no município de Campinas-SP.

As entrevistas foram analisadas segundo o referencial teórico e metodológico da história oral de vida, de modo que as narrativas passaram pelos processos de 1) transcrição literal, que consiste em converter o texto oral para o texto escrito; 2) textualização, em que foram suprimidos questionamentos e comentários do pesquisador, e corrigidos os erros e os vícios de linguagem da narrativa; 3) e transcriação, em que explicitamos o clima da entrevista, através da introdução das nossas impressões (MEIHY, 2010). Realizadas essas etapas, submetemos o texto final à apreciação dos colaboradores entrevistados, cumprindo as modificações por eles solicitadas. Somente após a aprovação do seu conteúdo por parte dos professores-colaboradores, o termo de consentimento autorizando o seu uso foi assinado.

Assim, partindo do pressuposto de que a trajetória de vida de uma pessoa, a despeito de suas individualidades, é também social, acreditamos que a análise da história oral de vida dos professores egressos desse curso nos permitiu delinear, a partir de suas narrativas, como a justiça restaurativa tem sido implementada enquanto uma política de Estado orientada à prevenção da violência escolar, como foi incorporada à prática docente e de que modo colabora tanto para o

\footnotetext{
${ }^{6}$ A figura do mediador foi instituída por meio do Sistema de Proteção Escolar (SPEC), através da Resolução SE no 19 , de 12-2-2010, depois reformulada pela Resolução SE $n^{\circ}$ 2, de 6-1-2017, cujas atribuições são definidas em seu artigo $7^{\circ}$, do seguinte modo:

“Art. $7^{\circ}$ - Na implementação das ações específicas do Sistema de Proteção Escolar, a escola poderá contar com 1 (um) docente para atuar como Professor Mediador Escolar e Comunitário, cujas atribuições consistem, precipuamente, em:

I - adotar práticas de mediação de conflitos no ambiente escolar e apoiar o desenvolvimento de ações e programas de Justiça Restaurativa;

II - orientar os pais dos alunos, ou responsáveis, sobre o papel da família no processo educativo;

III - analisar os fatores de vulnerabilidade e de risco a que possam estar expostos os alunos;

IV - orientar a família, ou responsáveis, quanto à procura de serviços de proteção social;

$\mathrm{V}$ - identificar e sugerir atividades pedagógicas complementares, a serem realizadas pelos alunos fora do período letivo;

VI - orientar e apoiar os alunos na prática de seus estudos.”. A Resolução SE no 19, de 12-2-2010, está disponível em:

<http://siau.edunet.sp.gov.br/ItemLise/arquivos/07_12.HTM>. Acesso em: 07 jul. 2016. A Resolução SE no 2, de 6-1-

2017, está disponível em: <http://siau.edunet.sp.gov.br/ItemLise/arquivos/2_17.HTM?Time=22/03/2017\%2015:19:48>. Acesso em: 21 out. 2017.

${ }^{7}$ Não existe um modelo padrão de "ser escola" (DAYRELL, 1996; SCHILLING, 2010, p. 3), cujas diferenças podem ser apontadas em sua arquitetura, nos seus projetos político-pedagógicos, e nos relacionamentos interpessoais; entretanto, nas narrativas dos professores, apenas as questões relativas aos relacionamentos interpessoais foram apontadas enquanto problema; ademais, o nível de precariedade nas escolas nas quais lecionavam era muito similar e remetia à escassez de recursos didáticos e tecnológicos. As unidades escolares de atuação dos professores certificados estavam localizadas em bairros situados nas regiões Leste e Sul, e em quatro Distritos do município de Campinas-SP.
} 
arrefecimento de tais situações neste lócus, como para o fortalecimento de um processo educativo orientado pelos direitos humanos e para o exercício ativo da cidadania.

\section{SOBRE AS CONCEPÇÕES DE DIREITOS HUMANOS E DE JUSTIÇA RESTAURATIVA DOS PROFESSORES}

Após três décadas do estabelecimento da democracia formal no Brasil, com a promulgação da Constituição Federal, em 1988, por meio da qual o País passa a ser signatário de importantes tratados internacionais ${ }^{8}$, como também passa a produzir um conjunto de Leis, programas, conferências e conselhos nacionais de proteção aos direitos humanos, uma análise sobre as nossas condições estruturais indica que os problemas relativos à sua efetivação persistem, embora estejam assegurados desde a perspectiva normativa (SCHILLING, 2014). É sobre isto que fala a professora Amanda:

Eu acredito que os direitos humanos, eles têm sim, uma função muito importante, mas a partir
do momento que eles cumprirem com a obrigação deles, aí eu acredito que está correto. Mas
eu não sei se cumpriram. Eu só sei através do que a mídia mostra... eu não procurei. Então,
dependendo do caso, dependendo da ocasião... Eu acho que a partir do momento que a pessoa
está pagando, eu estou usando aquilo que a gente mais ouve falar de direitos humanos, de
defender o bandido... a partir do momento que a pessoa foi julgada, vai pagar, ela tem que ter
dignidade também... ela já está pagando, ela não está solta, ela está lá presa no sistema prisional,
ela está em uma Fundação Casa, mas ela está pagando e eu acho que tem que ser digno. O
problema não são nem os direitos humanos, mas os direitos humanos que a gente não está
tendo, não é?

Esta compreensão da professora está sintonizada com os dados apresentados pela pesquisa Direitos bumanos: percep̧ões da opinião pública (VENTURI, 2010, p. 20). Nesta, ao serem questionados sobre quem são os sujeitos preferencialmente protegidos pelos direitos humanos, apenas um, em cada sete entrevistados (15\%) os associou com a defesa de infratores, compreendendo os direitos humanos como privilégio deste grupo específico. Entretanto, esta percepção colide com os 31\% dos entrevistados que se mostraram contrários aos direitos humanos dos presos (p. 25). Percentual que parece ser reforçado com a aquiescência de 34\% (somados os que concordam "totalmente" e "em parte") dos respondentes com a frase direitos humanos deveria ser só para pessoas direitas; e dos $32 \%$ que concordaram com a expressão bandido bom é bandido morto, percentual que se amplia para $43 \%$, quando somadas as respostas de quem concorda "parcialmente" com esta assertiva.

Ainda de acordo com esta pesquisa, dentre os direitos sugeridos como os mais desrespeitados, foram apontados: o direito à vida, à saúde, à proteção igual diante da lei, às liberdades de expressão e de ir e vir; e o tratamento paritário entre ricos e pobres, e entre brancos e negros (VENTURI, 2010, p. 21). Estes dados evidenciam incoerências nas respostas dos sujeitos entrevistados, pois $32 \%$ revelaram-se contrários às cotas para negros, por exemplo (p. 25).

As informações coletadas nesta pesquisa parecem indicar que em nossa sociedade existe uma clara percepção sobre quem deve ser incluído na universalidade dos direitos, de quem toleramos algumas violações dos direitos humanos - contexto que é muito bem expresso na fala da professora Suzana, quando afirma que "é o próprio processo político, a deseducação política do indivíduo que faz com que esses direitos humanos não sejam cumpridos".

\footnotetext{
8 Além da Declaração Universal dos Direitos Humanos, de 1948, o Brasil subscreveu a Convenção Internacional Contra a Tortura e Outros Tratamentos ou Penas Cruéis, Desumanos ou Degradantes, tanto a de 1948 como a de 1984; o Pacto Internacional sobre os Direitos Civis e Políticos, de 1966; o Pacto Internacional dos Direitos Econômicos, Sociais e Culturais, de 1966; a Convenção Internacional sobre a Eliminação de Todas as Formas de Discriminação Racial, de 1968; a Convenção sobre a Eliminação de Todas as Formas de Discriminação Contra as Mulheres, de 1979; a Convenção sobre os Direitos da Criança, de 1989; a Conferência Mundial de Viena, de 1993, só para citar alguns exemplos, pois a lista é bem extensa. No âmbito interamericano, o Brasil assinou a Declaração Americana de Direitos e Deveres do Homem, de 1948; a Convenção Americana sobre Direitos Humanos (Pacto de San José), de 1969; e o Protocolo de San Salvador, de 1988. Para uma análise mais detalhada de todos os documentos internacionais de direitos humanos ratificados pelo Brasil, ver o Plano Nacional de Educação em Direitos Humanos (PNEDH) (BRASIL, 2009, p. 67-69).
} 
Os dados apresentados pela pesquisa Direitos bumanos: percep̧cões da opinião pública (VENTURI, 2010) ensejam uma reflexão sobre o problema da efetivação dos direitos humanos e do estado democrático de direito no Brasil contemporâneo, como também sobre o papel a ser desempenhado pela educação nesse sentido.

Não obstante, abundantes dados analíticos evidenciam que o direito à educação ainda não foi devidamente concretizado entre nós, dada a persistência de graves indicadores de analfabetismo, distorção idade-série, reprovação e evasão dos alunos matriculados no ensino público (BRASIL, 2021; IBGE, 2019). Essa situação é especialmente emblemática, sobretudo ao considerarmos a educação tanto um direito humano como uma via para acessar outros direitos, uma vez que a noção de ser um sujeito de direitos não se realiza espontaneamente (PEREIRA, 2020; SCHILLING, 2004).

Nesse sentido, cumpre-nos destacar que no contexto da educação básica, a inclusão na legislação educacional da educação em direitos humanos é detalhada na Lei de Diretrizes e Bases da Educação Nacional (BRASIL, 1996, art. 26º, inc. IX), nos Parâmetros Curriculares Nacionais (BRASIL, 1997, p. 44), no Plano Nacional de Educação em Direitos Humanos (BRASIL, 2009, p. 25), nas Diretrizes Curriculares Nacionais para o Ensino Médio (BRASIL, 2012, art. 5, inc. III), no Plano Nacional de Educaşão (BRASIL, 2014, art. $2^{\circ}$, inc. X) e também na Base Nacional Comum Curricular ${ }^{9}$ (BRASIL, 2018, p. 19).

O Plano Nacional de Educação em Direitos Humanos (PNEDH), publicado oficialmente em 2006, que se constitui como marco legal da educação em direitos humanos no Brasil, recomenda que sejam incluídas no processo formativo informações acerca dos direitos humanos, dos tratados e das legislações que outorgam sua concretização, e dos meios necessários à sua efetivação (BRASIL, 2009). Um contato com essa perspectiva é apresentado por meio da fala do professor Gabriel:

Então, para mim os direitos humanos são referenciais fundamentais para qualquer pessoa que
queira romper com essas coisas formais que temos no Brasil e no mundo também, que é
aquela coisa de quem pode mais chora menos, eu sou melhor do que você porque sou homem,
porque tenho dinheiro, porque eu sou branco. Eu consigo romper essas coisas usando a
questão dos direitos humanos, sociais, políticos. Me falam que existe outro mundo, que
existem outras realidades e que são aceitas por causa de um conjunto histórico que impõe que,
quem está no poder manda, quem não está no poder obedece. E você só consegue romper isso
a partir do momento que você tem um conjunto de saberes, um conjunto de valores que te
indicam um caminho que você pode seguir, que você pode conseguir alterar essa realidade-
mundo.

E isto somente será possível, se considerarmos que o processo formativo possa se configurar enquanto um espaço adequado para a abordagem desses conteúdos no contexto escolar, como uma condição necessária à formação de sujeitos cônscios de seus direitos e deveres, essencial para o desenvolvimento de um verdadeiro estado democrático.

Se desde a perspectiva pedagógica se defende muito uma formação e educação orientadas para o exercício da cidadania, tal como expresso na Constituição Federal (BRASIL, 1988), na Lei de Diretrizes e Bases da Educaşão Nacional (BRASIL, 1996) e, mais recentemente, na Base Nacional Comum Curricular (2018), o que se observa é que, apesar de sua previsão legal, os princípios e valores concernentes aos direitos humanos geralmente não são abordados, nem vivenciados nas escolas públicas brasileiras (PEREIRA, 2020). Com efeito, afirma o professor João:

Até mesmo porque quando a gente fala em direitos humanos, a escola em si, ela não tem um
programa para o aluno, você não pega, por exemplo, um professor de História, ou qualquer
outra área, pode ser a de Biologia, de Ciências, que vá debater o Estatuto da Criança e do
Adolescente com o adolescente, ou com os funcionários da escola, ou em uma reunião com os
professores, para a gente debater naquilo ali, o que é que dá para ser utilizado, o que é que não
dá. Então aquilo dá uma certa bagagem para a gente fazer esse tipo de trabalho também com
os alunos, dizer para eles o que eles podem e o que eles não podem fazer, quais são os direitos

9 A tese foi defendida antes da promulgação da Base Nacional Comum Curricular (BNCC, 2018). Identificamos que na BNCC, os direitos humanos figuram como princípio orientador do currículo e também enquanto uma competência geral da educação básica. 
deles e quais são os deveres. Ou seja, no meu entendimento, politizar essa garotada, mostrar para ela que a vida não é apenas acordar, vir para a escola, copiar algumas coisinhas e pensar que está tudo certo, não, não é, a vida não é só isso, a vida não é só isso. Têm muitas questões que eles precisam aprender, que eles precisam discutir, tudo relacionado à comunidade que eles moram, a cidade que eles moram, o Estado que eles estão, o País que eles estão, tudo o que acontece no mundo acaba interferindo, por mais simples que o aluno seja, acaba chegando até ele, basta se falar em uma crise mundial que estava todo mundo dando risada. $\mathrm{E}$ o que aconteceu com aquele menos favorecido? Está aqui dentro da escola, a gente escuta eles falarem que o pai está desempregado, que não sei das quantas, então tudo acaba chegando até eles. E levando conhecimento até eles, eles sabem, eles vão saber para onde eles devem correr ou reivindicar, no caso, um direito que é deles. Visando melhorar a vida deles e fazer com que eles também adultos cumpram com a sua parte, que é o nosso dever.

Face ao evidenciado pelo professor, a escola, ao mesmo tempo em que pode reproduzir mecanismos relativos à dominação e à exclusão, também pode se constituir como um espaço decisivo para a construção de práticas de respeito aos direitos humanos, para a formação de uma consciência crítica e cidadã, e para o desenvolvimento de relacionamentos democráticos.

Entretanto, na narrativa dos professores entrevistados, identificamos a dificuldade em envolver todo o coletivo escolar nas propostas que implicam sua execução, seja pelo seu desconhecimento, seja pela ausência de tempo e vontade, seja pela fragilidade da rede de defesa, garantia e proteção de direitos para encaminhar os casos envolvendo agressões (verbais e físicas) sofridas pelos jovens, tal como nos relata a professora Antônia:

[...] quando às vezes nós precisamos da justiça, hoje nós temos aí o Conselho Tutelar, que não é órgão jurídico, ele não tem poder de nada, ele, na verdade, oferece um documento aqui de uma criança que vai ser abusada ou está sendo abusada, levo para eles, eles simplesmente pegam da nossa mão e levam para o promotor. Então demora, demora. Nós tivemos casos e casos aqui que a menina se perdeu, acabou, foi para o mundo e a justiça não se fez. Nós temos casos e casos que ficou por isso mesmo. Então nós nos sentimos, nesse aspecto, muito ainda sem amparo. É uma lástima isso, porque tanta coisa que a gente fala de direitos, indícios de leis e tudo o mais e quando a coisa explode na íntegra, eu afundo no caminho do Conselho Tutelar e eu não vejo solução. A gente tinha que ter o órgão da justiça mais aberto para a escola para uma solução imediata. Isso falta muito.

Assim, não obstante a introdução da justiça restaurativa no contexto educacional seja particularmente fecunda para a elaboração de um projeto formativo engajado em favor da formação de sujeitos aptos a exercerem ativamente sua cidadania, sobretudo no que concerne à resolução dos conflitos, ela se defronta com inúmeras ambiguidades neste lócus, pois, em sendo a escola uma instituição social, os problemas instalados na sociedade também se processam em seu interior e se manifestam cotidianamente sob as formas da violência e da exclusão (SCHILLING, 2014; SINGER, 2005), como se pode depreender do relato professor Jonas, ao dizer:

Eu acho que o mediador na escola ele é visto muito mais como um opressor do que como um mediador. Pela questão da autoridade, a autoridade reprime, oprime, dá medo. Pensa Deus aqui agora na sua frente. $E$ aí? Você sabe que Ele vai fazer assim... você vira pó. O poder dá medo, você estar diante de quem tem poder, dá medo. É uma espécie de temor piedoso, aquele temor reverente. É o temor do juiz, você sabe que se você falar alguma palavra fora do que ele espera ouvir, você pode ser preso por desacato a autoridade.

$\mathrm{Na}$ compreensão desse professor, se a justiça restaurativa é orientada, em meio escolar, suprimindo o diálogo, anulando o protagonismo dos sujeitos por meio da coerção, ela acaba por reproduzir a mesma violência que pretende prevenir, o que nos leva a refletir sobre a incidência das relações de poder no modo como tem sido implementada nas escolas.

Com este intuito, recorremos a Michel Foucault (1997, p. 119), que inicia seus estudos a respeito da "mecânica do poder" investigando o papel da disciplina em instituições como o presídio, o hospital, a fábrica e nas instituições educacionais, entre os séculos XVII e XIX, afirmando que o poder 
não pertence exclusivamente às instâncias de representação do Estado formalmente instituído, mas existe enquanto uma técnica disciplinar de dominação e sujeição dos corpos, cujos protagonistas são os indivíduos em suas interações diárias.

Em sendo esse um confronto assimétrico e perpétuo, incessantemente atravessado por uma "vontade de liberdade", que tanto é condição para o exercício do poder, como para a resistência a ele, e por ser essa uma relação agônica, no sentido de uma disputa permanente e recíproca entre adversários, o poder encontra seu ocaso quando, suprimida a liberdade, o que se instala é a relação autoritária - de modo que o poder, nesse caso, é substituído pela "coerção pura e simples da violência" (CASTELO BRANCO, 2013, p. 153; FOUCAULT, 1995, p. 244-245). Dessa maneira, a permanência, ou não, da dominação dependerá da correlação de forças, lutas e resistências que a ela se interponham.

Conforme afirma Veiga-Neto (2008, p. 20), Foucault possui uma interpretação ambígua sobre as relações de poder e de dominação: ao tempo em que afirma que as relações de dominação são relações de poder que se encontram cristalizadas e bloqueadas, de maneira que são muito pequenas as possibilidades de mudança e fuga daqueles que se encontram em situação de dominação (FOUCAULT, 2006), também afirma que as relações de poder são distintas dos estados de dominação (FOUCAULT, 1990, 1995, 2005).

A proposta de Veiga-Neto consiste, pois, em ressignificar o conceito de dominação na obra foucaultiana, haja vista que, em sua compreensão, as relações de dominação são relações de poder, mas elas o são em um outro nível: tratar-se-ia de uma diferença de intensidade cujo limite é a violência, mas essas relações não são estáticas. Em seu texto "O sujeito e o poder", afirma Foucault (1995) ${ }^{10}$ que, enquanto o poder disciplinar compreende a punição como uma ação racionalmente calculada, que tem por objetivo exercer o controle social sobre os indivíduos, a violência converte a punição em uma ação que se esgota nela mesma, ou seja, “[...] enquanto o poder dobra - porque se autojustifica e negocia e, com isso legitima -, a violência quebra - porque se impõe por si mesma. Enquanto aquele se dá agonisticamente, essa se dá antagonicamente" (VEIGA-NETO, 2008, p. 29, grifos do autor).

Assim também o conflito, a disputa, o agonismo de posições, de ideias e de formas de vida, devem, para Foucault (1995, p. 91), constituir-se como a tônica de nossas vidas, pois, se "onde há poder há resistência", para que existam relações de poder no sentido que este autor lhe atribui, é necessário que os sujeitos sejam livres, o que só é possível na medida em que existam circunstâncias pessoais, sociais e políticas factíveis para tal. "[...] O que não pode acontecer é a paralisia das relações agonísticas, pois isso representaria falta de mobilidade social e humana e privação de vivacidade democrática" (CASTELO BRANCO, 2013, p. 159).

Trouxemos essa interpretação de Veiga-Neto (2008) sobre a articulação entre os conceitos de dominação e poder na obra foucaultiana por considerarmos que ela atravessa o modo como os professores entrevistados negociaram os princípios da justiça restaurativa em suas práticas: em um gradiente, suas ações incidem ora em relações de poder, ora em dominação; em outros momentos, são as estratégias de luta a ocupar um papel protagônico, mas, frequentemente, suas ações apresentam-se matizadas. São as "formas minúsculas" (DUSCHATZKY, 2012, p. 88) de relação entre os professores e os alunos, por meio das quais buscam, com seus próprios recursos e em sua especificidade concreta, resolver os problemas que se lhes apresentam, a partir de sua apropriação dos princípios da justiça restaurativa. Isso se evidenciou em uma passagem do texto da entrevista do professor Lucas:

Esse é um ponto que me ajudou muito, que me encaminhou para a justiça restaurativa. Como os alunos também não são uma página branca, eles têm muitas dificuldades que eles trazem para o dia a dia na sala de aula. Eu tive uma aluna aqui no ano retrasado, que estava chorando na sala de aula e eu fui pedir para conversar com ela, fazia seis anos que ela não via o pai, aí fui questionar o porquê, até para a gente poder ajudar... 'meu pai está preso, faz seis anos que eu

\footnotetext{
${ }^{10}$ Nas palavras de Foucault (1995, p. 243): "Uma relação de violência age sobre um corpo, sobre as coisas; ela força, ela submete, ela quebra, ela destrói; ela fecha todas as possibilidades; não tem, portanto, junto de si, outro polo senão aquele da passividade; e, se encontra uma resistência, a única escolha é tentar reduzi-la. Uma relação de poder, ao contrário, se articula sobre dois elementos que lhe são indispensáveis por ser exatamente uma relação de poder: que 'o outro' (aquele sobre o qual ela se exerce) seja inteiramente reconhecido e mantido até o fim como o sujeito de ação; e que se abra, diante da relação de poder, todo um campo de respostas, reações, efeitos, invenções possíveis".
} 
não vejo meu pai'. Então, as histórias de vida que eles vão trazendo para a gente... eu já tive pessoas que usavam cocaína e entravam na sala de aula, alguns professores não conseguiam conversar e eu me dava muito bem com ele e fiquei feliz quando ele saiu daqui e eu o encontrei no comércio trabalhando, isso me deixou muito feliz porque eu sempre conversei com ele. E a justiça restaurativa quer que você sente, converse, tente ajudar de uma maneira que você não seja punitivo. E hoje eu penso assim, você conversa e na maioria das vezes, regras, limites, que em casa eles não conseguem encontrar, os alunos muitas vezes, não ouvem o 'não' na sua residência e quando eles chegam na sala de aula e que ouvem a palavra 'não', eles já ficam totalmente revoltados. Então eu penso que a justiça restaurativa é boa, mas o aluno tem que ser cobrado. Muitas vezes, você conversa três, quatro vezes com o aluno e você não consegue atingir o seu objetivo. Ah, você tem que punir o aluno? Eu não sei se é punir, mas você tem que delimitar limites e regras para ele. É o que eu procuro fazer hoje, se você for aí e perguntar, todos gostam de mim, mas eu procuro sentar, conversar e colocar limites, porque senão você não consegue, porque eles não vêm com esses limites da casa. Então vamos analisar a justiça restaurativa: só no diálogo, ela vai ser uma coisa que você vai conseguir a longo prazo e se você aliar o diálogo com as regras, eu penso que ela possa ser um pouco mais rápida, você vai conseguir alcançar algumas respostas.

É possível verificar nas narrativas dos professores acerca de suas práticas o que Duschatzky (2012, p. 89, tradução nossa) denomina como um impulso errante: esses professores não fogem aos problemas, o que se verifica é uma "disposição ativa para apropriar-se do que irrompe e agenciar algo em torno disso". É o que podemos observar nas palavras do professor Gabriel:

Por que se você tem um diálogo e você explica o porquê, qual é o papel, que mesmo que eu não goste eu sou obrigado a fazer tal coisa se acontecer isso, você está pelo menos escutando e colocando ao outro o que vai acontecer. E a partir do momento que você não fala e que você só fere, que você age com o rigor da lei, com a força, você causa conflitos. E se você não consegue resolver os conflitos, eles vão aumentando cada vez mais. E aí cabe a quem dá aula, que são as pessoas responsáveis em acalmar os conflitos, dialogar para que os conflitos sejam resolvidos. Só que até você conseguir isso, às vezes você perde o tempo da aula por causa de coisas que você não tinha que fazer. Só que como você quer o bem dos alunos e o bem da escola, você até abre mão da aula em si para resolver essa coisa que são as relações entre as pessoas que formam a escola, que no caso são os alunos, as pessoas que dão aula e a direção. Então, justiça na escola existe, é uma escola justa, mas podia ser bem melhor. A justiça restaurativa, ela veio para cá até para que a escola consiga agir melhor com esses alunos que ficam com raiva do mundo, ou que já vem com raiva do mundo e usam a escola para expor. Em casa às vezes não adianta expor porque em alguns casos a casa é só o físico mesmo, não tem aquela relação do pai e da mãe de chamarem o filho e a filha para ouvir, conversar, ensinar. É aquela coisa, "eu mando", “cala a boca”, geralmente pai que espanca a mãe com os filhos vendo, e aí o filho ou a filha não conseguem resolver isso em casa e na escola jogam isso com raiva, com revolta. Aí entra a história de você ouvir, "o quê que está havendo? Fala para mim. Porque eu posso chegar aqui e falar, falar e falar e vai entrar no seu ouvido e vai sair pelo outro, não vai adiantar nada, porque é você quem tem que falar, porque você não está bem, porque se você estivesse bem você não ia estar causando em sala ou na escola, como você está fazendo. Se você está fazendo isso e você sabe que vai chegar uma hora que você vai ter a sua atenção chamada ou que você vai acabar indo para a direção. Se você não consegue falar, não consegue articular, não consegue pedir, eu estou aqui, fala para mim, quê que está havendo”. E aí você consegue... nem sempre, mas você consegue com que essa pessoa abaixe as armas e que ela veja realmente a escola como um espaço dela, que ela pode usar a escola para virar aquilo que ela quer ser. Nesse caso, a justiça restaurativa foi importante, ela abriu os olhos de várias pessoas, até dos alunos mesmo, deles perceberem que há outras maneiras de agir. Então eu posso ser rebelde indo contra o mundo, chutando carteira, derrubando carteira, xingando minha amiga, xingando meu amigo, mas eu posso ser rebelde com o mundo sendo aquilo que eles não esperam que eu seja [...].

$\mathrm{Na}$ percepção dos professores, a justiça restaurativa atendeu às suas expectativas, coadunou-se com as suas disposições e foi incorporada às suas práticas, no sentido de que passaram a buscar resolver os conflitos por meio de práticas restauradoras. Como exemplo dessa construção, destacamos a fala da professora Suzana: 
Para você ter uma ideia, essa montanha de pastas aqui, é das férias para cá. Se você pega, você vê: "providência tomada". E sem ocorrência. A maioria é conversa e orientação ao aluno. Um caso ou outro de suspensão. E eu vejo que diminuiu muito a agressividade na escola, o compromisso com a frequência, eu acho que melhorou muito, muito. É a prática restaurativa que leva a isso. É a conversa, o acolhimento, é se colocar no lugar do outro, é chegar e chamar a direção, chamar o filho, mostrar que existem limites, que não é passar a mão na cabeça não, é um trabalho assim que é muito bom.

Por outro lado, também foi possível identificar em suas expressões que a sua execução em âmbito escolar está atravessada por inúmeros paradoxos: por exemplo, quando identificam a escola como excessivamente disciplinar, orientada por relações de poder punitivas e assimétricas, ou quando percebem a falta de vontade política e de tempo, condições necessárias para que as práticas restaurativas alcancem o coletivo escolar e tenham chances de se consolidarem nesse espaço. A propósito, destaco a narrativa do professor Marcos:

Então, a justiça restaurativa é a melhor forma de resolver, apesar da gente não conseguir colocar tudo em prática, é muito corrido, mas eu achei fundamental para mim, até pela formação como pessoa. Mas se eu tivesse que falar da justiça dentro da escola, eu diria que a justiça é punitiva, não só na escola, na sociedade, ela é muito punitiva, ela resolve as coisas reprimindo, às vezes até de forma autoritária. Para mim é justiça punitiva. A justiça restaurativa ainda é muito pequena. E como eu disse, a justiça é punitiva na sociedade em geral, no espaço social, não só na escola. Vou dar exemplos: o aluno chegou para o professor e foi malcriado com o professor, a medida é botar para fora, advertência, transferência compulsória, então é punitiva. Até os professores também, tem professores que são muito assim, coercitivos, mas não é só na relação professor/aluno, acho que em todas as relações. Tem essa relação de caráter assimétrico. As relações não são simétricas, como deveriam... Em uma sociedade democrática você tem que ser igual, não é por que ele é aluno que eu vou tratar ele como inferior, não é por que eu sou professor, que o diretor... Mas é assim que funciona, sempre assimétrica, eu falo em tom superior, vou lá pegar lanche, corto os alunos, é sempre assim... Em alguns casos eu acho que a justiça restaurativa, ela consegue restaurar sim, em outros não. Muitas vezes, uma conversa ali não violenta, fazendo os acordos, você vê que deu resultado. $\mathrm{O}$ menino bateu no menino, vai lá fazer um acordo, você percebe que não tem mais, mas tem casos que não, depois de fazer o acordo você vê que volta a repetir, volta a fazer. Então tem casos que funcionam e tem casos que não. Eu vejo um espaço para essa proposta no ambiente escolar. Não.... Na verdade não tem... o projeto é muito jogado, todo mundo trabalha muito, mediador trabalha muito, professor trabalha muito, então essas práticas... precisam de tempo, demandam tempo, do jeito que está, como o tempo é gerido, não. Você faz o que é possível, mas para funcionar precisaria ser melhor.

Donde se conclui que, muito embora acreditem que a justiça restaurativa tenha melhorado suas práticas pedagógicas e a maneira como passaram a lidar com os conflitos nas escolas, ainda assim evidenciam em suas narrativas que a sua realização no contexto escolar é permeada por autoritarismos e poderes que, de uma maneira geral, eles identificam na sociedade, nos poderes públicos, na escola, e, eventualmente, neles próprios.

Essa percepção encontra respaldo na narrativa apresentada pelos professores-mediadores, em que informam que a maioria dos casos enviados ou para a mediação ou para a direção da escola poderia ser solucionada em sala de aula. Embora compreendam que o cenário da sala de aula (salas superlotadas, excesso de conteúdos para dar conta, etc.) nem sempre permite ao professor resolver o conflito de maneira adequada, destacam que as relações de poder atravessam todas as relações vivenciadas no espaço escolar, como nos conta o professor João:

E os maiores conflitos da escola as pessoas pensam que são entre alunos, não é? Não é não, não é não. Os maiores conflitos que existem dentro da escola ocorrem entre professor, diretor, coordenador, entre aqueles que não deveriam ter esse tipo de conflitos. Entre eles. Lidar com aluno é a parte mais gostosa que tem na escola, conflito de aluno é conflito de adolescente, nós já sabemos, nós já passamos por isso. E quando nós começamos aplicar com eles, bacana, vai que é uma beleza, só que nós queremos também aplicar com os outros. Só que aí não, aí começa a fechar os espaços, não pode, não pode, não pode. E isso não é aqui e ali, isso é um 
contexto geral que vai, vai e vai e geralmente as pessoas acabam tolhendo aqueles que estão a fim de fazer, de praticar.

Se considerarmos a indisciplina e as situações de conflito e de violência na escola como reações e resistências por parte dos alunos contra as formas de assujeitamento e dominação (PEREIRA, 2020; GUIRARDO, 1996, p. 67-70; LEÃO, 2006, p. 41; SINGER, 2005, p. 178), interrogamos quais são as reais possibilidades de insurreição e de resistência para os alunos imersos em uma conjuntura tão claramente assimétrica, na qual "[...] a recusa a qualquer forma instituída é vista e vivida como uma conduta de resistência que requer ser governada” (SCHEINVAR, 2013, p. 146).

Em consonância com Foucault (1997), partindo do pressuposto de que a escola é um espaço que produz saber, poder, normalização e modos de subjetivação, a justiça restaurativa, enquanto uma prática operando nesse lócus, é também atravessada por diferentes estratégias de poder e de saberes que produzem efeitos de verdade na formação das subjetividades, o que, como vimos, tanto pode ensejar outros modos de controle - por meio, por exemplo, da "confissão" (no sentido de obrigar a falar a verdade) e da normalização (LARROSA, 2008) -, como também pode operar no âmbito da reflexão e da responsabilidade ativa dos sujeitos à qual originalmente se vincula. Nesse caso, o desafio consiste em garantir que a justiça restaurativa nesse espaço não se configure como um dispositivo que reproduza a violência, tal como ilustrado pelo professor Jonas:

O poder oprime. Então o mediador da escola, ele tem o poder de te suspender por uns dias, de colocar de castigo, etc. O mediador não pode ser assim, a pessoa tem que ter confiança na mediação. E na escola isso ainda está comprometido. Mesmo a mediadora aqui sendo uma professora, mas o cargo de mediador está incumbido de poder. Enquanto o poder não tem que ser dele, o poder tem que ser das pessoas que estão sendo mediadas, porque elas que estão resolvendo o problema entre si.

Ao considerarmos que a justiça restaurativa é geralmente conduzida na escola por gestores e/ou professores, e que as situações conflitivas são transformadas em relatórios para que sejam introduzidas tanto no livro de ocorrência das escolas, como em seu equivalente digital $\left(\mathrm{ROE}^{11}\right)$, concluiremos que as narrativas construídas acerca destes alunos também estão atravessadas por relações de poder e saber. Ademais, tomando como base as normas e regras estabelecidas tanto no Manual de Proteção Escolar e Promoção da Cidadania (SEESP, 2009a), como nas Normas Gerais de Conduta Escolar (SEESP, 2009b) ${ }^{12}$, forçoso é admitir que elas se contrapõem ao que é preconizado pela justiça restaurativa. Tais documentos foram concebidos pela Secretaria de Educação do Estado de São Paulo no marco do Sistema de Proteção Escolar (SPEC), que abrange sob sua rubrica a execução de um conjunto de programas e projetos de prevenção e combate à violência escolar, do seguinte modo definida na Resolução SE $n^{\circ}$ 19, de 12-2-2010 ${ }^{13}$, em seu artigo $1^{\circ}$ :

Fica instituído o Sistema de Proteção Escolar, que coordenará o planejamento e a execução de ações destinadas à prevenção, mediação e resolução de conflitos no ambiente escolar, com o objetivo de proteger a integridade física e patrimonial de alunos, funcionários e servidores, assim como dos equipamentos e mobiliários que integram a rede estadual de ensino, além da

\footnotetext{
11 “O ROE - Registro de Ocorrência Escolar é uma ferramenta on-line na qual os Diretores de Escola realizam o registro de ocorrências de cunho disciplinar e natureza delituosa no âmbito da comunidade escolar.” Para acessar o ROE é necessário ter login e senha, de modo que somente funcionários e pessoas autorizadas podem fazê-lo. Verificamos com a DRE Leste a possibilidade de acessá-lo, com o objetivo de analisar o que gestores e professores compreendem como violência e conflito, mas não nos autorizaram. Destacamos que esse sistema eletrônico foi instituído pelo artigo $9^{\circ}$ da Resolução SE $n^{\circ} 19$, de $12-$ 2-2010, a mesma que estabelece o Sistema de Proteção Escolar (SPEC). Disponível em: http://www.fde.sp.gov.br/PagePublic/Interna.aspx?codigoMenu=211. Acesso em: 25 mar. 2019.

12 Importante destacar que, de 15/09/2016 até o presente momento, o Manual e as Normas do Sistema de Proteção Escolar (SPEC), foram retirados do site sem nenhum tipo de justificativa. Para verificação, recomendamos a conferência no site que agora hospeda as informações sobre o SPEC: http://www.educacao.sp.gov.br/spec/o-sistema-de-protecao-escolar-spec/. Acesso em: 25 mar. 2019.

${ }^{13}$ A Resolução SE no 19, de 12-2-2010, encontra-se disponível em: http://siau.edunet.sp.gov.br/ItemLise/arquivos/19_10.HTM?Time=05/09/2016\%2018:19:44. Acesso em: 07 jul. 2016.
} 
divulgação do conhecimento de técnicas de Defesa Civil para proteção da comunidade escolar. (SEESP, 2010)

As orientações contidas no Manual de Proteção Escolar e Promoção da Cidadania (SEESP, 2009a), e nas Normas Gerais de Conduta Escolar (SEESP, 2009b), incluem desde a advertência verbal, a suspensão das atividades escolares e a transferência compulsória para outra Unidade Escolar, até o registro de Boletim de Ocorrência e o acionamento da polícia, para os casos que envolvem agressões físicas / verbais, uso de drogas, álcool (SEESP, 2009a, p. 33), depredação do patrimônio escolar, furto, roubo ou porte de armas (SEESP, 2009a, p. 35-36; 2009b, p. 13-14). As sanções disciplinares institucionalmente regulamentadas nestes documentos são autoritárias e punitivas, contrariando, portanto, a adoção de medidas preventivas e reparadoras, e consequentemente, o disposto pela justiça restaurativa (POSSATO, 2014, p. 37-39; TIBÉRIO, 2011, p. 83-90). Nas palavras do professor Jonas: "Então assim, 'ah, eu vou fazer as pazes com ele porque senão a diretora vai me colocar de suspensão', isso é uma justiça restaurativa? Não é. Isso é medo. A escola trabalha com medo".

Muito embora tenha existido consenso entre os professores - ainda que com graus variados de intensidade em afirmar que as práticas restaurativas "restauram" as relações em âmbito escolar, operando com base em advertências, punições, imposição de confissões, idas à diretoria, etc., em que medida podemos falar de restauração? Em termos foucaultianos, parece que nos movemos entre o terreno das relações de poder e o da dominação, haja vista que nesse contexto a justiça restaurativa também incorreria em violência, a mesma que pretende prevenir e arrefecer.

Assim, se no sistema escolar o processo pedagógico tem sido historicamente construído com base em um conjunto de práticas coercitivas face à insubmissão aos preceitos ou normas presentes na escola, este parece não estar funcionando, haja vista a crescente incidência e o agravamento das situações de violência que têm acometido o contexto escolar em suas mais diversas variações e condicionantes, as quais, associadas às dificuldades para enfrentá-las, têm evidenciado a profunda crise do papel da escola na atualidade e o permanente estado de tensão do trabalho docente em nossa sociedade (GUIMARÃES, 2003).

Nesse sentido, os professores relataram com sofrimento o impacto produzido pelos conflitos no exercício da docência. Sofrimento que se apresenta sob a forma de números bastante expressivos: em 2017, a Lei de Acesso à Informação indicava uma média de dois educadores agredidos por dia em seus locais de trabalho (em creches, escolas e em universidades, tanto particulares, como públicas), no estado de São Paulo; estes dados, obtidos por meio de registros policiais, foram contabilizados com base nas queixas prestadas por estes profissionais, no período de fevereiro a junho de 2017, em dias letivos do calendário escolar, e informavam que as ocorrências referiam-se tanto às "vias de fato" (violências consideradas menos graves, como empurrões, por exemplo), com 37\% das queixas, como aos crimes de lesão corporal, que contabilizaram 63\% dos registros (PINHO; MARIANI, 2017). O município de Campinas-SP, à época, ocupou a quinta posição nesse ranking, precedido pelas seguintes cidades: São Paulo (capital), Grande São Paulo (excluída a capital), Bauru e Ribeirão Preto. Interrogada a respeito, à época, a Secretaria de Educação informou o incremento em ações de mediação de conflitos. Mas em 2018 a Lei de Acesso à Informação reportou um aumento de $189 \%$ no registro de agressões, tanto verbais como físicas, desferidas contra professores de escolas da rede estadual paulista (CAVALCANTI, 2018).

Um exemplo de experiência bem-sucedida em mediação de conflitos tem sido desenvolvida em Barcelona (ES) ${ }^{14}$ : o Governo local estabelece que as escolas são independentes para decidirem o modo como vão realizar a "mediació escolar", mas oferecem um conjunto de formações e materiais

\footnotetext{
${ }^{14}$ No primeiro semestre de 2017, realizei estágio doutoral na Universitat Autònoma de Barcelona (UAB), com o objetivo de compreender como estavam situadas na trajetória profissional dos professores das redes de ensino pública e privada desta cidade, as noções de mediação de conflitos e cidadania. A escolha de realizar uma parte dos estudos na UAB deveu-se ao fato de que a legislação espanhola estabeleceu a mediação de conflitos como estratégia para a prevenção e para a superação da violência praticada nas escolas. Ademais, até o ano de 2016, a disciplina "Educação para a cidadania", era obrigatória no currículo do Ensino Secundário na região da Catalunha-ES. legislação espanhola estabeleceu a mediação de conflitos como estratégia para a prevenção e para a superação da violência praticada nas escolas.
} 
didáticos (disponibilizados gratuitamente na internet) para que a escola decida como e quando fazer, e o que utilizar, levando em conta a sua especificidade local; na legislação educacional consultada ${ }^{15}$, está previsto que, para realização da "mediació escolar", tanto os gestores como os professores e os alunos, devem passar por uma formação nas técnicas de mediação de conflitos, mas sua realização deve ocorrer entre iguais, de modo que o protagonismo em sua condução deve ser assumido pelos alunos: em cada sala de aula existem os alunos responsáveis pela mediação. Assim, quando há necessidade, os envolvidos os buscam e eles mesmos se restauram, ou seja, o que acontece entre os alunos, por eles mesmos é resolvido, sem envolver professores ou gestores; esses apenas acompanham a situação, ou nela intervêm, se são convocados pelos alunos, ou seja, quando estes percebem que uma determinada situação é mais grave ou delicada.

Não obstante as diferenças sociais, econômicas e políticas entre as culturas brasileira e espanhola, as técnicas restaurativas neste lócus já estão sendo colocadas em prática há algum tempo, o que nos permite pensar formas outras para sua implementação na realidade brasileira. E é por conta de exemplos como esse, que acreditamos ser possível pensar que a proposta da justiça restaurativa pode se dar em outros termos entre nós.

\section{DELINEANDO OS RESULTADOS ENCONTRADOS E TRAÇANDO ALGUMAS CONSIDERAÇÕES À GUISA DE CONCLUSÃO}

Não dispomos, na atual conjuntura, de quaisquer garantias quanto ao futuro dos direitos humanos entre nós, uma vez que as reformas que colocam em xeque direitos assegurados pela Constituição Federal (1988) vêm sendo implementadas mesmo em desacordo com a maioria da população. Donde se conclui que, embora coexistam em meio às reivindicações vocalizadas pelos movimentos sociais e por setores da sociedade civil organizada, as forças reacionárias à ampliação e à efetivação da agenda dos direitos humanos permanecem poderosas em um contexto marcado pelo autoritarismo, pelo paternalismo e pelo patrimonialismo (VENTURI, 2010). Essas perplexidades se verificam na execução dos direitos humanos e da justiça no Brasil, e, em sendo a escola uma instituição social, terminam por reproduzir-se nesses espaços.

Com o objetivo de tornar possível a resolução dos conflitos e a prevenção da violência no interior das unidades escolares, a formação "Cultura Restaurativa e suas Práticas", ofertada aos professores da rede estadual de educação do município de Campinas-SP, configurou-se como uma oportunidade para compreender o lugar que os direitos humanos e a justiça têm na história oral de vida dos professores egressos desse curso, a partir das quais suas noções acerca do que é justo e injusto, bom e mau, desejável e indesejável, são elaboradas em sua vida profissional.

Assim, recorremos à história oral de vida para refletir sobre suas práticas e sobre que efeitos de poder e saber produzem, que tipos de subjetividades formam, especialmente quando ocorrem no espaço concreto e heterogêneo que é a escola e objetivam a restauração das relações cujos protagonistas são os gestores, os professores e os alunos (CASTRO, 2016; FOUCAULT, 2014a, 2014b).

Embora tenha havido consenso sobre os benefícios da justiça restaurativa neste lócus, sobretudo no que diz respeito à introdução do diálogo, a grande maioria identifica ser este um trabalho

\footnotetext{
15 O projeto de convivência promulgado por meio da “RESOLUCIÓ ENS/585/2017”, em 17 de março de 2017, estabelece que "os centros educacionais devem formar todos os alunos e os membros da comunidade escolar para convivência e gerenciamento positivo dos conflitos”, cujos objetivos são os seguintes:

- Assegurar e garantir a participação, envolvimento e compromisso de toda a comunidade escolar.

- Ajudar cada aluno a se relacionar consigo mesmo, com os outros e com o mundo.

- Promover a equidade e o respeito pela diversidade de estudantes em um quadro de valores compartilhados.

- Incentivar a mediação escolar e a cultura do diálogo como ferramenta básica no gerenciamento de conflitos.

- Promover uma cultura de paz e da não-violência, juntamente com os valores que permitem preservar e enriquecer a vida de todas as pessoas.

A íntegra do documento está disponível

$<$ http://educacio.gencat.cat/portal/page/portal/Educacio/PCentrePrivat/PCPInici/PCPProjectesEducatius/PCPProjecte

Convivencia>. Acesso em: 29 jul. 2017.
} 
realizado solitariamente - ou porque falta tempo e espaço para envolver todo o coletivo escolar na proposta, ou porque não há interesse por parte do coletivo em se envolver. Ademais, percebem excesso de autoridade por parte dos gestores e dos professores na escola; consideram que não existe imparcialidade nas relações escolares; que a intervenção no conflito geralmente se dá pela imposição da obediência, ou da confissão; e, por fim, o fato de associarem a introdução do diálogo em suas práticas pedagógicas após a sua participação no curso sobre a justiça restaurativa é também bastante emblemático. Em menores percentuais, apresentaram percepções favoráveis aos direitos humanos: em âmbito escolar, atribuíram sua ausência à formação técnica e despolitizada dos professores; na sociedade, associaram as violações a esses direitos ao desconhecimento e à falta de educação política.

Ou seja: o que podemos verificar nas narrativas dos professores é que as práticas restauradoras ou se dão em contextos marcados por relações de poder e autoritarismos, ou são por elas atravessadas. Nesse sentido, consideramos que a ausência de uma cidadania ativa e a relação conturbada com os direitos humanos no Brasil contemporâneo terminam por comprometer a realização de ações orientadas à justiça restaurativa, sobretudo na prática escolar, espaço no qual consideramos que elas deveriam ser ensinadas e professadas. Não obstante tenhamos identificado práticas que até tentam solucionar os conflitos, verificamos que o modo pelo qual são conduzidas não empodera os sujeitos, tampouco os prepara para o agonismo de posições da esfera pública, pois são exercidas com base nos dispositivos de controle e retroalimentam nesse lócus a mesma violência que pretendem arrefecer. Mas como promover deslocamentos nessa direção? Como resistir aos discursos reguladores do trabalho dos professores?

Com o intuito de esboçar uma resposta à primeira pergunta, Veiga-Neto chama atenção, em registro foucaultiano, para a compreensão de que os discursos e as ações estão sempre e necessariamente envolvidas em relações de poder. Como não há um "fora do poder", do mesmo modo como não estamos incessantemente enredados em situações de dominação, sempre será possível exercer uma resistência, “[...] uma (re)ação ou, se quisermos, como uma ação de contrapoder. Resistir a uma ação de poder significa problematizar tal ação, valendo-se, para isso, também do poder" (VEIGANETO, 2008, p. 22). E, em sendo assim, temos que atentar para que os discursos e também as práticas que os sustentam não venham a se constituir como violências, sobretudo quando se pretende, através do diálogo, resolver as situações de conflito e prevenir a violência em âmbito escolar, por meio da justiça restaurativa.

Defendemos que a instituição escolar deveria ser espaço para a aprendizagem e a vivência da cultura democrática, haja vista a insuficiência de espaços para o exercício da vivência da vida pública. E como pode o jovem aprender a ser sujeito na vida democrática? Quais esforços têm sido envidados para que os jovens se tornem sujeitos de suas próprias vidas? Essas deveriam ser perguntas incessantemente formuladas pelas escolas, e é nessa perspectiva que as questões relativas à violência não deveriam ser reduzidas apenas à dimensão da segurança pública, mas tratadas como um assunto político e cultural. No momento em que a noção de público perde força, quando desaparece a dimensão de sociabilidade e as razões para "estarmos juntos", ganha força a compreensão de que a violência pode ser um recurso legítimo para a solução dos conflitos (CARRANO, 2007).

Assim, um dos grandes desafios da atualidade passou a ser educar para que os indivíduos reconheçam a si e aos demais em espaços públicos democráticos (CARRANO, 2007). E, para tanto, é necessário encorajar a agência docente (PIGNATELLI, 2008), no sentido de estimular entre os educadores uma reflexão permanente que coloca sob suspeita concepções totalizadoras, com vistas a transformar rotinas escolares, a refletir sobre o que pode ser feito nas circunstâncias nas quais atuam, cotidianamente, e, até mesmo, a partir daí para engajar-se em favor de mudanças mais amplas na própria sociedade.

\section{REFERÊNCIAS}

BRASIL. Constituição Federal, $1988 . \quad$ Disponível em: http://www.planalto.gov.br/ccivil_03/constituicao/constitui\%C3\%A7ao.htm. Acesso em: Acesso em: 07 jan. 2011. 
BRASIL. Lei de Diretrizes e Bases da Educação Nacional [LDB n 9.394]. Brasília: Presidência da República, 1996. Disponível em: <portal.mec.gov.br/arquivos/pdf/ldb.pdf>. Acesso em: 3 jan. 2009.

BRASIL. Parâmetros Curriculares Nacionais: introdução aos parâmetros curriculares nacionais [PCNs]. Brasília: Ministério da Educação/Secretaria de Educação Fundamental, 1997. Disponível em: <http://portal.mec.gov.br/seb/arquivos/pdf/livro01.pdf>. Acesso em: 15 fev. 2011.

BRASIL. Plano Nacional de Educação em Direitos Humanos [PNEDH]. Brasília: Secretaria Especial dos Direitos Humanos, Ministério da Educação, Ministério da Justiça, UNESCO, 2009.

BRASIL. Resolução no 2, de 30 de Janeiro 2012. Define Diretrizes Curriculares Nacionais para o Ensino Médio. Brasília: Ministério da Educação, 2012. Disponível em: http://pactoensinomedio.mec.gov.br/images/pdf/resolucao_ceb_002_30012012.pdf. Acesso em: 30 nov. 2012.

BRASIL. Plano Nacional de Educação [PNE], 2014-2024. Brasília: Presidência da República, 2014. Disponível em:

http://presrepublica.jusbrasil.com.br/legislacao/125099097/lei-13005-14. Acesso em: 15 jan. 2015.

BRASIL. Base Nacional Comum Curricular. Brasília: MEC, 2018. Disponível em: http://basenacionalcomum.mec.gov.br/images/BNCC_EI_EF_110518_versaofinal_site.pdf Acesso em: 3 jan. 2021.

BRASIL. Instituto Nacional de Estudos e Pesquisas Educacionais Anísio Teixeira. Censo da Educação Básica 2020: notas estatísticas. Brasília: INEP, 2021. Disponível em:

http://inep.gov.br/informacao-da-publicacao/-

/asset_publisher/6JYIsGMAMkW1/document/id/6993024. Acesso em: maio 2021.

CARRANO, Paulo Cézar Rodrigues. Educação de jovens e adultos e juventude: o desafio de compreender os sentidos da presença dos jovens na escola da "segunda chance". REVEJ@: Revista de Educação de Jovens e Adultos, Belo Horizonte, v. 1, n. 0, p. 55-67, 2007. Disponível em: http://www.reveja.com.br/sites/default/files/REVEJ@0_PauloCarrano.pdf. Acesso em: 05 fev. 2019.

CASTELO BRANCO, Guilherme. Agonística e palavra: as potências da liberdade. In: CASTELO BRANCO, Guilherme; VEIGA-NETO, Alfredo (org.). Foucault: filosofia e política. 1 reimpr. Belo Horizonte: Autêntica, 2013. p. 153-161.

CASTRO, Edgardo. Vocabulário de Foucault: um percurso pelos seus temas, conceitos e autores. 2. ed. Belo Horizonte: Autêntica, 2016.

CATALUNYA. RESOLUCIÓ ENS/585/2017, de 17 de março, per la qual s'estableix l'elaboració $i$ la implementació del Projecte de Convivència en els centres educatius dins el marc del Projecte Educatiu de Centre. Disponível em: http://portaldogc.gencat.cat/utilsEADOP/PDF/7336/1599535.pdf. Acesso em: 29 jul. 2017.

CAVALCANTI, Tatiana. Casos de agressão a professores crescem 189\% no estado de São Paulo. Folha de S. Paulo, São Paulo, SP: 2018. Disponível em: https://www1.folha.uol.com.br/educacao/2018/08/casos-de-agressao-a-professores-crescem-189-noestado-de-sao-paulo.shtml. Acesso em: 05 fev. 2019. 
CHAUI, Marilena. Manifestações ideológicas do autoritarismo brasileiro. 2. ed. Belo Horizonte: Autêntica; São Paulo: Editora Fundação Perseu Abramo, 2014.

DAYRELL, Juarez Tarcísio. A escola como espaço sócio-cultural. In: DAYRELL, Juarez (org.). Múltiplos olhares sobre educaşão e cultura. Belo Horizonte: Ed. UFMG, 1996. p. 136-161.

DUSCHATZKY, Silvia. Maestros errantes: experimentaciones sociales en la intemperie. Buenos Aires: Paidós, 2012.

FOUCAULT, Michel. Tecnologías del yo y otros textos afines. Barcelona: Paidós Ibérica, 1990.

FOUCAULT, Michel. O sujeito e o poder. In: DREYFUS, Hubert; RABINOW, Paul. Michel Foucault: uma trajetória filosófica. Rio de Janeiro: Forense Universitária, 1995. p. 231-249.

FOUCAULT, Michel. Vigiar e punir: nascimento da prisão. 33. ed. Petrópolis: Vozes, 1997.

FOUCAULT, Michel. História da sexualidade 1: vontade de saber. 16. ed. Rio de Janeiro: Graal, 2005.

FOUCAULT, Michel. A ética do cuidado de si como prática da liberdade. In: Ética, sexualidade, política. Rio de Janeiro: Forense Universitária, 2006. p. 264-287. (Ditos \& escritos, v. 5).

FOUCAULT, Michel. História da sexualidade 2: o uso dos prazeres. Rio de Janeiro: Paz \& Terra, 2014a.

FOUCAULT, Michel. Prefácio à história da sexualidade. In: Genealogia da ética, subjetividade e sexualidade. Rio de Janeiro: Forense Universitária, 2014b. p. 207-213. (Ditos \& escritos, v. 9).

GUIMARÃES, Áurea Maria. Vigilância, Punição e Depredação Escolar. Campinas: Papirus, 2003.

GUIRARDO, Marlene. Poder indisciplina: os surpreendentes rumos da relação de poder. In: AQUINO, Julio Groppa (org.). Indisciplina na escola: alternativas teóricas e práticas. 16. ed. São Paulo: Summus, 1996.

IBGE. Pesquisa nacional por amostra de domicílios contínua (PNAD Contínua), 2019. Disponível em: https://biblioteca.ibge.gov.br/visualizacao/livros/liv101736_informativo.pdf. Acesso em: maio 2021.

LARROSA, Jorge. Tecnologias do eu e educação. In: SILVA, Tomaz Tadeu da (org.). O sujeito da educação: estudos foucaultianos. 6. ed. Petrópolis: Vozes, 2008. p. 35-86.

LEÃO, Geraldo Magela Pereira. Experiências da desigualdade: os sentidos da escolarização elaborados por jovens pobres. Educação e Pesquisa, São Paulo, v. 32, n. 1. p. 31-48, 2006.

MARTINS, Maria do Carmo. E se o Outro é o professor? Reflexões acerca do currículo e histórias de vida. In: GALLO, Sílvio; SOUZA, Regina Maria de (org.). Educaşão do preconceito: ensaios sobre poder e resistência. Campinas: Alínea, 2004. p. 103-118.

MEIHY, José Carlos Sebe Bom. Memória, história oral e história. In: Revista de História Oral. São Paulo, ano 4, n. 8, p. 179-191, 2010.

MELO, Eduardo Rezende. Comunidade e justiça em parceria para a promoção de respeito e civilidade nas relações familiares e de vizinhança: um experimento de justiça restaurativa e comunitária. Bairro Nova Gerty, São Caetano do Sul/SP. In: SLAKMON, Catherine; MACHADO, Maíra Rocha; BOTTINI, Pierpaolo Cruz (org.). Novas direções na governança da justiça e da segurança. Brasília: Ministério 
da Justiça, 2006. p. 59-80. Disponível em: http:/ /www.cejamericas.org/Documentos/DocumentosIDRC/156JuizadosEspeciaisoprocessoinexora veldamudanca.pdf. Acesso em: 15 mar. 2015.

ORGANIZAÇÃO DAS NAÇÕES UNIDAS [ONU]. Declaração Universal dos Direitos Humanos [DUDH], 1948. Disponível em:

http:/ /www.oas.org/dil/port/1948\%20Declara\%C3\%A7\%C3\%A3o\%20Universal $\% 20 \mathrm{dos} \% 20$ Direitos \%20Humanos.pdf. Acesso em: 27 jan. 2011.

OXHORN, Philip; SLAKMON, Catherine. Micro-justiça, desigualdade e cidadania democrática. A construção da sociedade civil através da justiça restaurativa no Brasil. In: SLAKMON, Catherine; VITTO, Renato Campos Pinto de; PINTO, Renato Sócrates Gomes (org.). Justiça restaurativa. Brasília: Ministério da Justiça, Programa das Nações Unidas para o Desenvolvimento - PNUD, 2005. p. 189212. Disponível em: https://www.ufpe.br/ppgdh/images/documentos/jrestaurativa.pdf. Acesso em: 15 mar. 2015.

PEREIRA, Ana Carolina Reis. Direitos Humanos, Justiça Restaurativa e Violência Escolar. Judiaí: Paco Editorial, 2020.

PINHO, Ângela; MARIANI, Daniel. SP tem quase 2 professores agredidos ao dia; ataque vai de soco a cadeirada. Folba de S. Paulo, São Paulo, 17 set. 2017. Disponível em: http://www1.folha.uol.com.br/educacao/2017/09/1919146-sp-tem-quase-2-professores-agredidos-aodia-ataque-vai-de-soco-a-cadeirada.shtml. Acesso em: 11 nov. 2017.

PIGNATELLI, Frank. Que posso fazer? Foucault e a questão da liberdade e da agência docente. In: SILVA, Tomaz Tadeu da (org.). O sujeito da educaşão: estudos foucaultianos. 6. ed. Petrópolis: Vozes, 2008. p. 127-154.

POSSATO, Beatris Cristina. O "professor mediador escolar e comunitário": uma mirada a partir do cotidiano escolar. 2014. 195 f. Tese (Doutorado em Educação) - Universidade Estadual de Campinas, Campinas. Disponível em: http://www.bibliotecadigital.unicamp.br/document/?code=000931149. Acesso em: 05 maio 2015.

RUOTTI, Caren; ALVES, Renato; CUBAS, Viviane de Oliveira. Violência na escola: um guia para pais e professores. São Paulo: Andhep; Imprensa Oficial do Estado de São Paulo, 2006.

SCHEINVAR, Estela. Biopolítica e judicialização das práticas de direitos: conselhos tutelares em análise. In: CASTELO BRANCO, Guilherme; VEIGA-NETO, Alfredo (Orgs.). Foucault: filosofia e política. 1 reimpr. Belo Horizonte: Autêntica, 2013. p. 143-151.

SCHILLING, Flávia. Violência na escola: reflexões sobre justiça, igualdade e diferença. In: HENNING, L. M. P.; ABBUD, M. L. M. (org.). Violência, indisciplina, educação. Londrina: EDUEL, 2010. p. 127-138.

SCHILLING, Flávia. Educação e direitos humanos: percepções sobre a escola justa. São Paulo: Cortez, 2014.

SCHILLING, Flávia. A sociedade da insegurança e a violência na escola. São Paulo: Moderna, 2004.

SECRETARIA DA EDUCAÇÃO DO ESTADO DE SÃO PAULO (SEESP). Manual de proteção escolar e promoção da cidadania. São Paulo: FDE, 2009a. Disponível em: http://www.educacao.sp.gov.br/spec/wpcontent/uploads/2013/09/protecao_escolar_web.pdf.

Acesso em: 21 set. 2014. 
SECRETARIA DA EDUCAÇÃO DO ESTADO DE SÃO PAULO (SEESP). Normas gerais de conduta escolar. São Paulo: FDE, 2009b. Disponível em: http://file.fde.sp.gov.br/portalfde/Arquivo/normas_gerais_conduta_web.pdf. Acesso em: 21 set. 2014.

SECRETARIA DA EDUCAÇÃO DO ESTADO DE SÃO PAULO (SEESP). Resolução SE n 19, de 12-2-2010. Institui o sistema de proteção escolar na rede estadual de ensino de São Paulo e dá providências correlatas. Disponível em: http://siau.edunet.sp.gov.br/ItemLise/arquivos/19_10.HTM?Time=05/09/2016\%2018:19:4. Acesso em: 07 jul. 2016.

SECRETARIA DA EDUCAÇÃO DO ESTADO DE SÃO PAULO (SEESP). Resolução SE $n^{\circ} 07$ de 19-1-2012. Dispõe sobre o exercício das atribuições de professor mediador escolar e comunitário do sistema de proteção escolar, e dá outras providências. Disponível em: http://siau.edunet.sp.gov.br/ItemLise/arquivos/07_12.HTM. Acesso em: 07 jul. 2016.

SINGER, Helena. Direitos humanos na escola: a escola democrática. In: SCHILLING, Flavia (org.). Direitos humanos e educaşão: outras palavras, outras práticas. São Paulo: Cortez, 2005. p. 177-185.

TIBÉRIO, Wellington. A judicialização das relações escolares: um estudo sobre a produção de professores. 2011. 155 f. Dissertação (Mestrado em Educação) - Universidade de São Paulo, São Paulo. Disponível em: http://www.teses.usp.br/teses/disponiveis/48/48134/tde-04082011-143218/pt-br.php. Acesso em: 15 jul. 2016.

VEIGA-NETO, Alfredo. Dominação, violência, poder e educação escolar em tempos de Império. In: RAGO, Margareth; VEIGA-NETO, Alfredo (org.). Figuras de Foucault. Belo Horizonte: Autêntica, 2008. p. 14-38.

VENTURI, Gustavo (org.). Direitos humanos: percepções da opinião pública. Brasília: Secretaria de Direitos Humanos, 2010. p. 9-31. Disponível em: http://www.biblioteca.presidencia.gov.br/publicacoes-oficiais/catalogo/lula/direitos-humanospercepcoes-da-opniao-publica-2010/view. Acesso em: 05 fev. 2017.

VITTO, Renato Campos Pinto de. Justiça criminal, justiça restaurativa e direitos humanos. In: SLAKMON, Catherine; VITTO, Renato Campos Pinto de; PINTO, Renato Sócrates Gomes (org.). Justiça restaurativa. Brasília: Ministério da Justiça, Programa das Nações Unidas para o Desenvolvimento - PNUD, 2005. p. 41-52. Disponível em: https://www.ufpe.br/ppgdh/images/documentos/jrestaurativa.pdf. Acesso em: 15 mar. 2015. 